\title{
Bioactive Conjugated Linoleic Acid (CLA) in Milk
}

\author{
Jun-III Kee, Palanivel Ganesan, and Hae-Soo Kwak* \\ Department of Food Science and Technology, Sejong University, Seoul 143-747, Korea
}

\begin{abstract}
Conjugated linoleic acid (CLA) isomers are found naturally in foods, such as milk, milk products, beef and others, from biohydrogenation of vegetable oils. They are heterogenous group of isomers of linoleic acid in the family of polyunsaturated fatty acids. Among the isomers of linoleic acid cis9, trans11- CLA (c9, t11-CLA) and trans10, cis12- CLA (t10, c12-CLA) are found to be biologically active isomers. These biologically active isomers either individual or combined found to be health beneficial in various diseases, such as cancer, diabetes, obesity, and atherosclerosis, conclusive participation in physiological processes are necessary. This review focused on the current study of CLA in prevention of disease, such as cancer, diabetes and atherosclerosis, and their effective function in body fat reduction, improvement of bone and muscle mass at a cellular, clinical and systematic level.
\end{abstract}

Key words: CLA, bioactive, cancer, obesity, atherosclerosis

\section{Introduction}

Bioactive lipid components with health beneficial properties are seen widely in bovine milk lipids (Park, 2009) and ruminant meat products such as beef (Benjamin et al., 2005; Benjamin and Spener, 2009). Among the several milk bioactive lipid components conjugated linoleic acids (CLA) has gained more importance to nutritionists and researchers in recent years due to enhancement of health benefits, which includes anticarcinogenic, antidiabetic and antiatherogenic (Benjamin and Spener, 2009; Carvalho et al., 2010; Reynolds and Roche, 2010). The beneficial effects of milk CLA in dietary are mainly attributed to two CLA isomers which include cis-9, trans11 (c9, t11-CLA) and trans-10, cis-12 (t10, c12-CLA), their structure is shown in Fig. 1. The c9, t11-CLA isomer constitutes up to $90 \%$ of total CLA and found to be predominant for their health benefits (Reynolds et al., 2008). The t10, c12-CLA isomer accounts for $1-10 \%$ of total CLA from dietary sources (Choi et al., 2004) and it is mainly concern with the anti-obesity role (Park et al., 2007; Whigham et al., 2007). Mixture of these isomers with in daily intake of 3.0 to 3.5 grams also proved to be

\footnotetext{
*Corresponding author: Hae-Soo Kwak, Department of Food Science and Technology, Sejong University, Seoul 143-747, Korea. Tel: +82-2-3408-3226, Fax: +82-2-3408-4319, E-mail: Kwakhs@sejong.ac.kr
}

anticarcinogenic in humans (Collomb et al., 2004).

CLA and its natural isomer rumenic acid have multiple anti-tumorigenic effects and is a potent inhibitor of mammary tumour development (Parodi, 2003). The isomer specific and their mixture effects have been defined in a wide range of inflammatory based disorders including inflammatory bowel disease (IBD) (Bassaganya-Riera and Hontecillas, 2006), diabetes (Halade et al., 2010; Zhou et al., 2008) and atherosclerosis (Nakamura et al., 2008). However, some results showed undesirable metabolic changes in various trials (Andreoli et al., 2009). Further CLA used as a functional food is also banned in a certain country such as Brasil (Brasil, 2007) due to insufficient scientific study, regarding the safety in human trials. This review focuses on the current research relating to the health benefits of milk bioactive CLA isomers.

\section{Bioactive CLA in Milk and Proposed Molecular Mechanism}

Milk fat is the highest source of CLA and contents ranging from 2 to $53.7 \mathrm{mg} / \mathrm{g}$ fat have been reported in various studies (Collomb et al., 2006). The broad range of CLA values are due to the different factors such as feeding, locations and breed of cow or sheep or goat. The different CLA isomers do not necessarily exhibit the same biological effects (Martin and Valeille, 2002). In milk fat, c9, t11-CLA amounts to $75-90 \%$ of total CLA, 

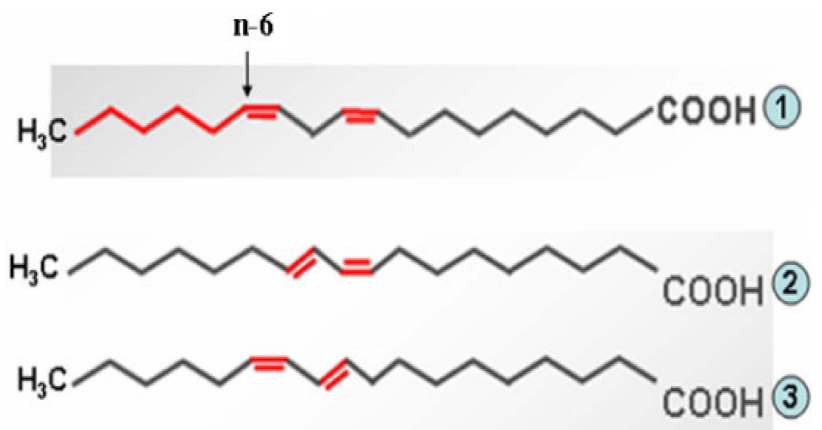

Fig. 1. Structure of linoleic acid and its major CLA derivatives (Benjamin and Spener, 2009). 1. Linoleic acid (typical n-6 PUFA); 2. cis-9,trans-11-octadecadienoic acid (9-CLA, in fact an n-7 fatty acid); 3. trans-10, cis12-octadecadienoic acid (10-CLA).

Table 1. Percentage of CLA isomers in cow milk fat

\begin{tabular}{ccc}
\hline \hline No & CLA Isomers & Percentage (\%) \\
\hline 1 & $\mathrm{c} 9, \mathrm{t} 11$ & $76.5-83.5$ \\
2 & $\mathrm{c} 7, \mathrm{t} 9$ & $3.6-6.7$ \\
3 & $\mathrm{t} 11, \mathrm{t} 13$ & $2.3-4.2$ \\
4 & $\mathrm{t} 9, \mathrm{t} 11$ & $1.5-2.0$ \\
5 & $\mathrm{t} 12, \mathrm{t} 14$ & $0.9-2.8$ \\
6 & $\mathrm{t} 7, \mathrm{t} 9$ & $0.6-2.4$ \\
7 & $\mathrm{t} 10, \mathrm{t} 12$ & $0.5-0.6$ \\
8 & $\mathrm{c} 10, \mathrm{t} 12$ & $0.4-1.1$ \\
9 & $\mathrm{c} 12, \mathrm{t} 14$ & $0.4-0.8$ \\
10 & $\mathrm{c} 8, \mathrm{t} 10$ & $0.3-1.0$ \\
11 & $\mathrm{t} 8, \mathrm{t} 10$ & $0.3-0.4$ \\
12 & $\mathrm{t} 10, \mathrm{c} 12$ & $<0.1$ \\
13 & $\mathrm{c} 11, \mathrm{t} 13$ & - \\
\hline
\end{tabular}

Kraft et al. (2003), Parodi (2003), and Khanal (2004).

whereas t10, c12- CLA constitutes a minor isomer and are shown in Table 1. The health benefits of CLA are concerned with the above two isomers and their mixtures are shown in Fig. 2. The molecular level action of CLA lies mainly on the CLA mediated range of biochemical pathways (Benjamin and Spener, 2009) which are shown in Fig. 3. However, this evidence was inconclusive and elaborate studies should be undertaken (Benjamin and Spener, 2009).

\section{CLA Role on Anticancer}

Milk and other source of CLA has been proven to decrease cancer in a number of animal models, such as breast, liver, skin, fore stomach and mammary, along with fewer study on human subjects (Bhattacharya et al., 2006; Kelley et al., 2007; Park, 2009). Among the CLA isomers c9, t11-CLA and t10, c12- CLA have been shown in animal models to inhibit mammary tumour initiation, promotion and progression (Ip et al., 2002). It cures cancer very fast and proven in various types of tumors include malignant and benign. Some researcher undergoes in vitro studies and proved to reduce the growth of human breast cancer cell lines (Ip et al., 2002; Wang et al., 2005). Both in vitro and in vivo studies shows either individual or mixtures have cytotoxic effects against cancer cells (Park et al., 2000) but little human data are available so far. A very little approach in human colorectal studies shows CLA has best ant proliferative effects. The mechanism and prevention of carcinogen is rather complex and very numerous. CLA may play a various preventing role such as inhibiting DNA synthesis as well as inhibiting angiogenesis reducing eicosanoids production, as shown in reduced matrix metallo-proteinases and vascular endothelial growth factors (Bhattacharya et al., 2006; Kelley et al., 2007).

Dr. Pariza's group reported about CLA anticancer activity from ground beef extract. However, the role of milk CLA in cancer was conducted initially by Knekt et

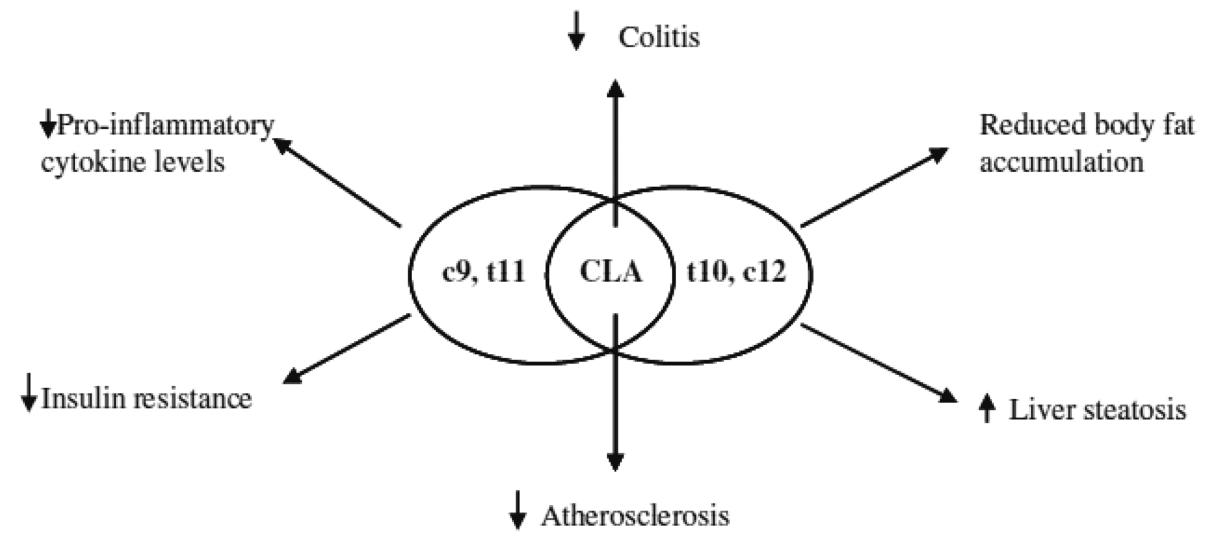

Fig. 2. Health effects of c9,t11-CLA,t10,c12-CLA and mixed CLA isomers (Reynolds and Roche, 2010). 


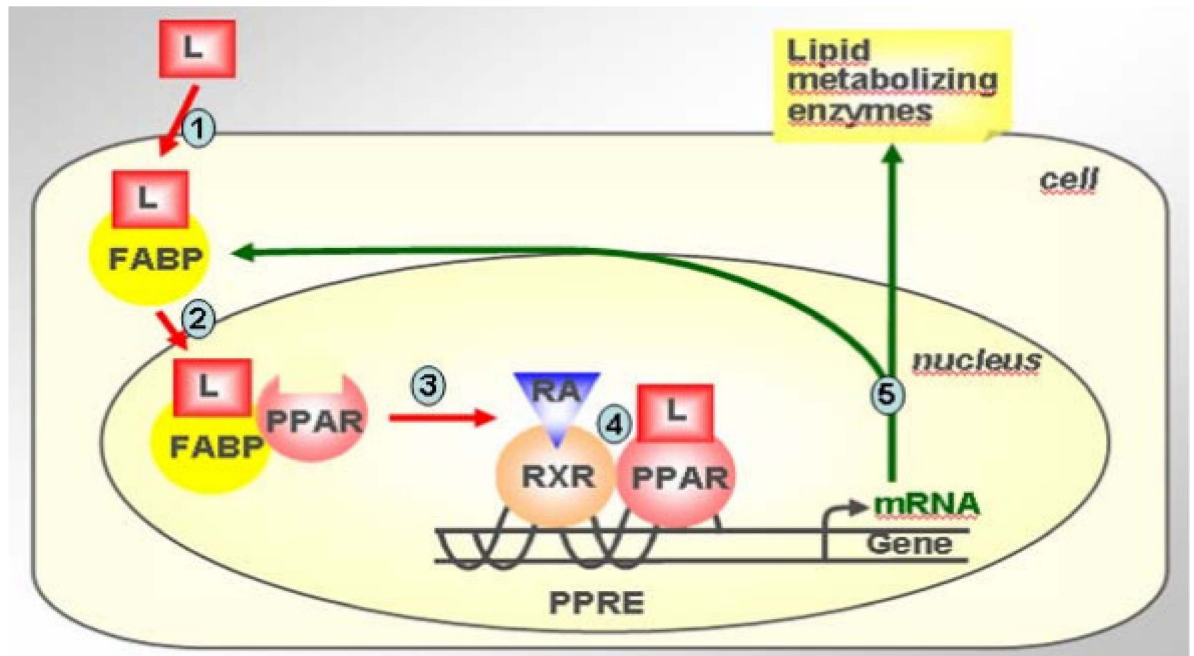

Fig. 3. Proposed CLA-mediated signal transduction (Benjamin and Spener, 2009). The dietary lipid nutrient L (L = here CLA) crossing the cell membrane with the help of specific membrane-bound fatty acid transporters and binds to tissue-specific fatty acid binding protein (FABP) in the cytosol; 2. The L/FABP complex enters in to the nucleoplasm, where $\mathrm{L}$ is transferred to the specific peroxisome proliferators activated receptor (PPAR) subtype; 3. The L/PPAR complex heterodimerises with retinoic acid (RA)/retinoic acid receptor (RXR) subtype; 4. This heterodimer binds to the peroxisome proliferator responsive element (PPRE) on the target gene; and 5. Specific gene expression occurs, whose products act intra- or extracellularly to elicit a host of various biological functions.

al. (1996) which provide indirect evidence of role of milk CLA intake against breast cancer in human. From then many researchers have published the role of CLA in milk against breast cancer with various mechanisms such as inhibition the growth of ER $\alpha(+) \mathrm{MCF}-7$ and $\mathrm{ER} \alpha()$ MDA-MB-231 human breast cancer cells by negative modulation of the ERK/MAPK pathway and apoptosis induction (Bocca et al., 2007). Though the above studies strengthen the beneficial effects but the mechanism are complex and numerous. Some researchers found the inhibitory effect with CLA rich diet in postmenopausal women (Aro et al. 2000) while many researchers found very less correlation between CLA and risk of breast cancer as noted by CLA levels in body or estimation by food intake data (McCann et al., 2004; Rissanen et al., 2003; Voorrips et al., 2002). In cell culture studies, c9, t11-CLA inhibited tumor necrosis factor and promoted insulinstimulated glucose transport in 3T3-L1 adipocytes. Some other studies prove that high CLA enriched fat diets may reduce the risk of colorectal cancer (Larsson et al., 2005). However, variation in the effects of CLA is due to multiple factor, such as type of CLA, organ and stage of carcinogen (Lee et al., 2005).

\section{CLA Role on Antidiabetics}

Disease management of the type II diabetics can be done efficiently by the supplement of CLA with little metabolic effects. The syndrome includes varies metabolic abnormalities such as centralobesity, insulinresistance, microalbuminurea elevated triacylglycerol (TAG) concentrations, and hypertension. According to the review of Belury (2003), the bioactive isomer t10, c12-CLA serve as an effective control of body weight in type II diabetus mellitus subject. The t10, c12-CLA exerts a series of delipidation process which ultimately inhibits glucose and metabolism through a series of molecular actions by down regulating the expression of PPAR $\gamma$ and its downstream targets that are essential for fatty acid and glucose metabolism (Benjamin and Spener, 2009). However, this isomer also causes liver steatosis and insulin resistance (Wendel et al., 2008). Poirier et al. (2006) also informed that t10, c12-CLA can lead to the induction of insulin resistance. Several studies have demonstrated that the positive anti-diabetic effects associated with CLA are isomer specific and the c9, t11-CLA isomer has anti-inflammatory, insulin sensitizing effect. Moloney et al. (2007) also prove that $\mathrm{c} 9, \mathrm{t} 11$-CLA is very effective in insulin resistance of obese mice. The markers of insulin resistance including fasting plasma glucose and TAG concentrations were all greatly reduced in the c9, t11-CLA. From the review of Reynolds and Roche (2010), a caution must be taken before consumption of CLA on basis of health benefits in related to the antidiabetic role. 


\section{CLA Role on Antiatherosclerosis}

CLA mixtures and individual isomers have been shown for health promoting effects in animal models of atherosclerosis (Reynolds and Roche, 2010), such as reducing atherosclerotic lesions (Jones et al., 2009; Wilson et al., 2006). Blending of CLA isomers showed reduction level of atherosclerotic lesions in male mice ApoE deficient (Toomey et al., 2006). The possible mechanism of decreasing atherosclerosis by (a) enhance in high density lipoprotein cholesterol (HDL) through enhances in apo A-I and apo A-II synthesis, reduce in atherogenic lipoprotein plasma levels such as very low (b) reduction of vascular inflammation by repressing nuclear NF $k \mathrm{~B}$ and apo A-I transcriptional activity and they would reduce thrombosis risk by inhibiting tissue factor and fibrinogen synthesis and (c) overexpression in HDL receptors capable of enhancing cellular cholesterol efflux (Akahoshi et al., 2004; Benjamin and Spener, 2009). The supplementation of dietary CLA in rodents can decrease serum cholesterol and led to reduction of cholesterol which can enhance atherosclerotic lesions severity in Aorta. However, individual isomers has variable effects in reduction of atherosclerosis, such as c9, t11-CLA, showed reduced lesion size, whereas t10, c12-CLA showed increased lesion in Apo E deficient mice (Reynolds and Roche, 2010).

\section{CLA Role on Body Fat Reduction, Improve- ment of Muscle and Bone Mass}

CLA's effect on body fat reduction and improvement of better health is suggested to be the result of various mechanisms: by increasing energy expenditure, by modulating adipokines and cytokines, such as leptin, TNF- $\alpha$, adiponectin, or interleukins and by reducing lipid accumulation in adipose tissues and/or adipocytes differentiation (Park and Pariza, 2007). The effct of CLA on body fat reduction varies among the species of animals. The t10, c12-CLA isomer seems to be responsible for milk fat depression syndrome in cows due to the feeding of high amount of unsaturated plant and fish oils which ultimately lead to the reduced milk fat production (Larsen et al., 2003). But it can enhance muscle content of swine body by effective improvement for the redistribution of nutrient. In certain animal study, the t10, c12-CLA isomer is found to decrease the fat mass and increase the insulin resistance and lean mass, but c9, t11-CLA isomer inhibit the insulin resistance (Halade et al., 2010). However, some reports show that consumption of CLA enhances 3 fold levels of plasma lipids (Doyle et al., 2005). This marked difference in health aspects due to the isomer specific effects of CLA (Benjamin and Spener, 2009).

Mixed CLA isomers showed various effects on bone formation may be due to the different isomers present in preparations of CLA. Watkins et al. (2004) also reported that bone formation rate increased in tibia by the addition of CLA to a considerable amounts of dietary n-6 polyunsaturated fatty acids (PUFAs). It proves that effects of dietary CLA on bone formation could be based on the stage of development, the isomer composition, the type of fat in the diet and making up the balance of PUFAs (Watkins et al., 2004). CLA also effect the cytokines, and it may act as a good tool in the reduction of symptoms of Rheumatoid (Hur and Park, 2007). It may not only prevent bone loss, accretion of fat mass but also prevent the reduction of muscle mass during aging (Rahman et al., 2009). In animal study, the bone mass of rat can increase when the rat fed with CLA supplemented with calcium (Park et al., 2008).

\section{CLA Role on Antioxidant Activity}

Antioxidant activity of CLAs in lipid autoxidation has been extensively studied but without any clear conclusions. The contradictory conclusions due to the presence of both trans configuration and conjugated double bond which may lead to stability and initiation of lipid autoxidation which can serve as pro-oxidant (Santos-Zago et al., 2008). The possible way of explaining CLA antioxidant activity is based on the anticarcinogenic and antiatherogenic effect by suppressing their free radical (Fagali and Catala, 2008). It may also serve as useful food antioxidants and provide additional value because of their potential bioactivity in disease prevention (Badr El-Din and Omaye, 2007). According to Santos-Zago et al. (2008), the CLA are more oxidative stable the PUFA in vitro studies. However, Yang et al. (2009) reported that CLA isomers have more oxidative instability than corresponding non conjugated linoleic acid.

In recent years, fewer animal studies were conducted and proven that most of the CLA isomers have antioxidant activity with various mechanisms. The determination of certain antioxidant enzymes and thiobarbituric acid reactive substances (TBARS) in mice fed with CLA can prove the antioxidant activity (Santos-Zago et al., 2008). Dietary supplement of CLAs can enhance antioxidative balance in chicks with oxidized stress and also increasing oxidative stability in plasma and hepatic mem- 
brane in the vitamin E-deficient rats (Kim et al., 2005). The measurement of antioxidant enzymes activity showed increase values of SOD activity in brain and liver of CLA treated groups indicating possible antioxidant activity (Carvalho et al., 2010). Rahman et al. (2009) also confirms that different CLA isomers either individual such as t10, c12-CLA or mix can increase higher muscle antioxidant enzyme (CAT and GSH-Px) production which accompanied by an enhancement in $\mathrm{H}_{2} \mathrm{O}_{2}$. It can also maintain redox balance during aging process (Rahman et al., 2009). However, further research should be focused to study individual isomers of CLAs and its role of health benefits in various foods. Another function of CLA is also studied concerned with antiatherogenic actions and some metabolites of CLA mediated this action (Ringseis, 2006). In cell culture studies, c9, t11-CLA modifies the adhesion of macrophages and also the induction of IL$1 \mathrm{Ra}$ is partly responsible for the anti-atherogenic properties of this CLA isomer (Lee and Vanden Heuvel, 2010).

\section{Conclusion}

The consumption of milk and other dairy products were found to be health beneficial on related to CLA. The main two CLA isomers can act either as an individual or mix which often have different metabolic and cell signaling effects on both in vitro and in vivo that may lead to complexity. Further, the complex mechanisms lead to be beneficial in certain disease such as cancer, diabetics and obesity. This encouraging effect of CLA isomers may also open a wide range in the functional foods without possibly omitted.

\section{Acknowledgements}

This study was supported by a grant of the Brain Korea 21 Project in Seoul, Republic of Korea.

\section{References}

1. Akahoshi, A., Koba, K., Ichinose, F., Kaneko, M., Shimoda, A., Nonaka, K., Iwata, T., Yamauchi, Y., Tsutsumi, K., and Sugano, M. (2004) Dietary protein modulates the effect of CLA on lipid metabolism in rats. Lipids 39, 25-30.

2. Andreoli, M. F., Gonzalez, M. A., Martinelli, M. I., Mocchiutti, N. O., and Bernal, C. A. (2009) Effects of dietary conjugated linoleic acid at high-fat levels on triacylglycerol regulation in mice. Nutrition 25, 445-452.

3. Aro, A., Mannisto, S., Salminen, I., Ovaskainen, M. L., Kataja, V., and Uusitupa, M. (2000) Inverse association between dietary and serum conjugated linoleic acid and risk of breast cancer in postmenopausal women. Nutr. Cancer 38, 151-157.

4. Badr El-Din, N. K. and Omaye, S. T. (2007) Concentration dependent anti-oxidant activities of conjugated linoleic acid and $\alpha$-tocopherol in corn oil. J. Sci. Food Agric. 83, 23152320.

5. Bassaganya-Riera, J. and Hontecillas, R. (2006) CLA and n3 PUFA differentially modulate clinical activity and colonic PPAR-responsive gene expression in a pig model of experimental IBD. Clin. Nutr 25, 454-465.

6. Belury, M. A. (2003) Conjugated linoleic acids in type 2 diabetes mellitus: implications and potential mechanisms. In: Advances in Conjugated Linoleic Acid Research, Sebedio, J., Christie, W.W., Adlof, R. (eds.), AOCS, Champaign, IL, USA, Vol. 2, pp. 302-315.

7. Benjamin, S. and Spener, F. (2009) Conjugated linoleic acid as functional food: an insight into their health benefits. Nutr. Metab. 6, 36-48.

8. Benjamin, S., Hanhoff, T., Börchers, T., and Spener, F. (2005) A molecular test system for the screening of human PPAR transactivation by conjugated linoleic acid isomers and their precursor fatty acids. Eur. J. Lipid Sci. Technol. 107, 706-715.

9. Bhattacharya, A., Banu, J., Rahman, M., Causey, J., and Fernandes, G. (2006) Biological effects of conjugated linoleic acids in health and disease. J. Nutr. Biochem. 17, 789-810.

10. Bocca, C., Bozzo, F., Francica, S., Colombatto, S., and Miglietta, A. (2007) Involvement of PPAR gamma and Ecadherin/beta-catenin pathway in the antiproliferative effect of conjugated linoleic acid in MCF-7 cells. Int. J. Cancer 121, 248-256.

11. Brasil (2007) Ministério da Saúde. Agência Nacional de Vigilância Sanitária - ANVISA. Resolução nº 833, 28 de março de. Resolve Determinar a apreensão, em todo território nacional, de todos os lotes do produto ácido linoléico conjugado - CLA, por não possuir registro no Ministério da Saúde. Diário Oficial da União, Brasília, DF, 29 mar. 2007. Seção 1, p. 68.

12. Carvalho, E. B. T., Melo, I. L. P., and Mancini-Filho, J. (2010) Chemical and physiological aspects of isomers of conjugated fatty acids. Ciencia e Tecnologia de Alimento. 30, 295-307.

13. Choi, J. S., Jung, M. H., Park, H. S., and Song, J. (2004) Effect of conjugated linoleic acid isomers on insulin resistance and mRNA levels of genes regulating energy metabolism in high-fat-fed rats. Nutrition 20, 1008-1017.

14. Collomb, M., Schmid, A., Sieber, R., Wechsler D., and Ryhänen, E. L. (2006) Conjugated linoleic acid in milk fat: Variation and physiological effects. Int. Dairy J. 16, 13471361.

15. Collomb, M., Sieber, R., and Butikofer, U. (2004) CLA isomers in milk fat from cows fed diets with high levels of unsaturated fatty acids. Lipids. 39, 355-364.

16. Doyle, L., Jewell, C., Mullen, A., Nugent, A. P., Roche, H. M., and Cashman, K. D. (2005) Effect of dietary supplemen- 
tation with conjugated linoleic acid on markers of calcium and bone metabolism in healthy adult men. Eur. J. Clin. Nutr. 59, 432-440.

17. Fagali, N. and Catala, A. (2008) Antioxidant activity of conjugated linoleic acid isomers, linoleic acid and its methyl ester determined by photoemission and DPPH techniques. Biophys. Chem.13, 56-62.

18. Halade, G. V., Rahman, M. M., and Fernandes, G. (2010) Differential effects of conjugated linoleic acid isomers in insulin-resistant female $\mathrm{C} 57 \mathrm{Bl} / 6 \mathrm{~J}$ mice. J. Nutr. Biochem. 21, 332-337.

19. Hur, S. J. and Park, Y. (2007) Effect of conjugated linoleic acid on bone formation and rheumatoid arthritis. Eur. $J$. Pharmacol. 568, 16-24.

20. Ip, C., Dong, Y., Ip, M. M., Banni, S., Carta, G., Angioni, E., Murru, E., Spada, S., Melis, M. P., and Saebo, A. (2002) Conjugated linoleic acid isomers and mammary cancer prevention. Nutr. Cancer 43, 52-58.

21. Jones, A., Deb, R., Torsney, E., Howe, F., Dunkley, M., Gnaneswaran, Y., Gaze, D., Nasr, H., Loftus, I. M., Thompson, M. M., and Cockerill, G. W. (2009) Rosiglitazone reduces the development and rupture of experimental aortic aneurysms. Circulation 119, 3125-3132.

22. Kelley, N. S., Hubbard, N. E., and Erickson, K. L. (2007) Conjugated linoleic acid isomers and cancer. J. Nutr. 137, 2599-2607.

23. Khanal, R. C. (2004) Potential health benefits of conjugated linoleic acid (CLA): A review. Asian-Austral. J. Anim. Sci. 17, 1315-1328.

24. Kim, H. K., Kim, S. R., Ahn, J. Y., Cho, I. J., Yoon, C. S., and Ha, T. Y. (2005) Dietary conjugated linoleic acid reduces lipid peroxidation by increasing oxidative stability in rats. $J$. Nutr. Sci. Vitaminol. (Tokyo). 51, 8-15.

25. Knekt, P., Jarvinen, R., Seppanen, R., Pukkala, E., and Aromaa. A. (1996) Intake of dairy products and the risk of breast cancer. Br. J. Cancer 73, 687-691.

26. Kraft, J., Collomb, M., Möckel, P., Sieber, R., and Jahreis, G. (2003) Differences in CLA isomer distribution of cows' milk lipids. Lipids 38, 657-664.

27. Larsen, T. M., Toubro, S., and Astrup, A. (2003) Efficacy and safety of dietary supplements containing conjugated linoleic acid (CLA) for the treatment of obesity-evidence from animal and human studies. J. Lipid Res. 44, 2234-2241.

28. Larsson, S. C., Bergkvist, L., and Wolk, A. (2005) High-fat dairy food and conjugated linoleic acid intakes in relation to colorectal cancer incidence in the Swedish Mammography Cohort. Am. J. Clin. Nutr. 82, 894-900.

29. Lee, K. W., Lee, H. J., Cho, H. Y., and Kim, Y. J. (2005) Role of the conjugated linoleic acid in the prevention of cancer. Crit .Rev. Food Sci. Nutr. 45, 135-144.

30. Lee, Y. and Vanden Heuvel, J. P. (2010) Inhibition of macrophage adhesion activity by 9 trans, 11 trans-conjugated linoleic acid. Inhibition of macrophage adhesion activity by 9trans, 11 trans-conjugated linoleic acid. J. Nutr. Biochem. 21, 490497.

31. Martin, J. C. and Valeille, K. (2002) Conjugated linoleic acids: all the same or to everyone its own function? Reprod. Nutr. Dev. 42, 525-536.

32. McCann, S. E., Ip, C., Ip, M. M., McGuire, M. K., Muti, P., Edge, S. B., Trevisan, M., and Freudenheim, J. L. (2004) Dietary intake of conjugated linoleic acids and risk of premenopausal and postmenopausal breast cancer, Western New York Exposures and Breast Cancer Study (WEB Study). Cancer Epidemiology, Biomarkers \& Prevention: A Publication of the American Association for Cancer Research. Cosponsored by the American Society of Preventive Oncology 13, 1480-1484.

33. Moloney, F., Toomey, S., Noone, E., Nugent, A., Allan, B., Loscher, C. E., and Roche, H. M. (2007) Antidiabetic effects of cis-9, trans-11-conjugated linoleic acid may be mediated via anti-inflammatory effects in white adipose tissue. Diabetes 56, 574-582.

34. Nakamura, Y. K., Flintoff-Dye, N., and Omaye, S. T. (2008) Conjugated linoleic acid modulation of risk factors associated with atherosclerosis. Nutr. Metab. (London). 21, 5-22.

35. Park, Y. and Pariza, M. W. (2007) Mechanisms of body fat modulation by conjugated linoleic acid (CLA). Food Res. Int. 40, 311-323.

36. Park, Y., Albright, K. J., Storkson, J. M. Liu, W., and Pariza, M. W. (2007) Conjugated linoleic acid (CLA) prevents body fat accumulation and weight gain in an animal model. $J$. Food Sci. 72, 612-617.

37. Park, Y., Pariza, M. W., and Park, Y. (2008) Co-supplementation of dietary calcium and conjugated linoleic Acid (CLA) improves bone mass in mice. J. Food Sci. 73, 556-560.

38. Park, Y., Storkson, J. M., Ntambi, J. M., Cook, M. E., Sih, C. J., and Pariza, M. W. (2000) Inhibition of hepatic stearoylCoA desaturase activity by trans-10, cis- 12 conjugated linoleic acid and its derivatives. Biochim. Biophys. Acta. 1486, 285292.

39. Park, Y. (2009) Bioactive components in milk and Dairy products.1st ed, John Wiley \& Son Pub., Iowa, p. 426.

40. Parodi P. W. (2003) Anti-cancer agents in milk fat. Aust. J. Dairy Technol. 58, 114-118.

41. Poirier, H., Shapiro, J. S., Kim, R. J., and Lazar, M. A. (2006) Nutritional supplementation with trans-10, cis-12-conjugated linoleic acid induces inflammation of white adipose tissue. Diabetes 55, 1634-1641.

42. Rahman, M. M., Halade, G. V., El Jamali, A., and Fernandes, G. (2009) Conjugated linoleic acid (CLA) prevents age-associated skeletal muscle loss. Biochem. Biophys. Res. Commun. 383, 513-518.

43. Reynolds, C. M. and Roche, H. M. (2010) Conjugated linoleic acid and inflammatory cell signaling. Prostaglandins Leukot. Essent Fatty Acids 82, 199-204.

44. Reynolds, C. M., Loscher, C. E., Moloney, A. P., and Roche, H. M. (2008) Cis-9, trans-11-conjugated linoleic acid but not its precursor trans-vaccenic acid attenuate inflammatory markers in the human colonic epithelial cell line Caco-2. Br. J. Nutr. 100, 13-17.

45. Ringseis, R., Muller, A., Herter, C., Gahler, S., Steinhart, H., and Eder, K. (2006) CLA isomers inhibit TNF alpha-induced 
eicosanoid release from human vascular smooth muscle cells via a PPAR-gamma ligand- like action. Biochim. Biophys. Acta 1760, 290-300.

46. Rissanen, H., Knekt, P., Jarvinen, R., Salminen, I., and Hakulinen, T. (2003) Serum fatty acids and breast cancer incidence. Nutr. Cancer 45, 168-175.

47. Santos-Zago, L. F., Boteho, A. P., and Oliveira, A. C. (2008) Os efeitos do ácido linoléico conjugado no metabolismo animal: avanço das pesquisas e perspectivas para o futuro. Revista. de Nutrição. 21, 195-221.

48. Toomey, S., Harhen, B., Roche, H. M., Fitzgerald, D., and Belton, O. (2006) Profound resolution of early atherosclerosis with conjugated linoleic acid. Atherosclerosis 187, 40-49.

49. Voorrips, L. E., Brants, H. A., Kardinaal, A. F., Hiddink, G., Van den Brandt, J., and Goldbohm, P. A. (2002) Intake of conjugated linoleic acid, fat, and other fatty acids in relation to postmenopausal breast cancer: the Netherlands Cohort Study on Diet and Cancer. Am. J. Clin. Nutr. 76, 873-882.

50. Wang, H. Y., Qu, P., Lu, S., Liu, M., and Jiang, H. (2005) The effects of TLR4/NF-kappaB activatioin and LOX-1 on monocyte adhesion to endothelium. Zhonghua Xin Xue Guan Bing Za Zhi. 33, 827-831.

51. Watkins, B. A., Li, Y., Lippman, H. E., and Seifert, M. F.
(2004) A test of Ockham's razor: implications of conjugated linoleic acid in bone biology. Am. J. Clin. Nutr. 79, 11751185.

52. Wendel, A. A., Purushotham, A., Liu, L. F., and Belury, M. A. (2008) Conjugated linoleic acid fails to worsen insulin resistance but induces hepatic steatosis in the presence of leptin in ob/ob mice. J. Lipid Res. 49, 98-106.

53. Whigham, L. D., Watras, A. C., and Schoeller, D. A. (2007) Efficacy of conjugated linoleic acid for reducing fat mass: a meta-analysis in humans. Am. J. Clin. Nutr. 85, 1203-1211.

54. Wilson, T. A., Nicolosi, R. J., Saati, A., Kotyla, T., and Kritchevsky, D. (2006) Conjugated linoleic acid isomers reduce blood cholesterol levels but not aortic cholesterol accumulation in hypercholesterolemic hamsters. Lipids $\mathbf{4 1}$, 41-48.

55. Yang, L., Cao, Y., Chen, J. N., and Chen, Z. Y. (2009) Oxidative Stability of conjugated linolenic acids. J. Agric. Food Chem. 57, 4212-4217.

56. Zhou, X. R., Sun, C. H., Liu, J. R., and Zhao, D. (2008) Dietary conjugated linoleic acid increases PPAR gamma gene expression in adipose tissue of obese rat, and improves insulin resistance. Growth Horm. IGF Res. 18, 361-368.

(Received 2010.11.23/Revised 2010.12.16/Accepted 2010.12.22) 